\title{
Alandan not
}

\section{İkinci basamak bir devlet hastanesinde erişkin bağışıklama ünitesi deneyimi}

\author{
İrem Akdemir Kalkana, Fethiye Akgülb, Güle Çınarc, Osman Memikoğluc ${ }^{c}$, Alpay \\ Azapc
}

\author{
a Öğr.Gör. Dr., Ankara Ü., Tıp Fakültesi, Enfeksiyon Hastalıkları ve Klinik Mikrobiyoloji AD.,Ankara, Türkiye \\ ${ }^{b}$ Dr., Batman Bölge Devlet Hastanesi \\ ${ }^{c}$ Dr., Ankara Ü., Tıp Fakültesi, Enfeksiyon Hastalıkları ve Klinik Mikrobiyoloji AD.,Ankara, Türkiye
}

Geliş tarihi: 11.11.2018, Kabul tarihi: 21.05.2019

\section{$\ddot{0 ̈ z}$}

Amaç: Aşı ile önlenebilir hastalıklardan korunmanın sağlanması toplum sağlığı açısından oldukça önemlidir. Fakat ülkemizde erişkin bağışıklama konusunda uygulamada önemli eksiklikler mevcuttur. Bu çalıșmada ikinci basamak bir devlet hastanesi olan Batman Bölge Devlet Hastanesinde kurulan 'Erișkin Bağıșıklama Ünitesi'nin deneyimleri aktarılmıștır. Yöntem: Kasım 2017-Şubat 2018 tarihleri arasındaki 3 aylık süreçte ünitede yapılan Hepatit A, Hepatit B ve konjuge pnömokok aşıları aşı yapılan kişilerin epidemiyolojik özellikleri, aşı endikasyonları ve yönlendirildikleri klinikler açısından analiz edilmiştir. Bulgular: Kayıtlarının retrospektif incelemesinde toplamda 85 hastaya aşı yapıldığı saptandı. Bu hastaların \%35.3’ü (n=30) kadın olarak saptandı. Hastaların tümü 16 yaş üzeri idi. Yaş ortalaması 57.6 olarak saptandı. Yapılan aşıların dağılımına bakıldığında \%80 (n=68) hastanın konjuge pnömokok aşısı ile aşılandığı, \%17.6 (n=15) hastaya Hepatit $B, \% 2.4(n=2)$ hastaya ise hepatit A aşısı uygulandığı görüldü. Aşılama endikasyonlarına bakıldığında $\% 5.9(n=5)$ hasta 65 yaş üstü olması nedeni ile, \%36.5 $(\mathrm{n}=31)$ hasta böbrek yetmezliği nedeni ile, \%1.2 $(\mathrm{n}=1)$ hasta romatolojik tedavi adayı olması nedeni ile, \%8.2 (n=7) birey evde riskli temaslı birey-tümü Hepatit B açısından- olması nedeni ile, $\% 4.7(n=4)$ birey ise sağlık personeli olduğu için aşılanırken, \%42.4 $(n=36)$ birey ise başta KOAH olmak üzere altta yatan akciğer hastalıkları nedeni ile aşılanmış olarak tesbit edilmiştir. Sonuç: Erişkin Bağışıklama Merkezleri' ikinci ve üçüncü basamak sağlık hizmeti veren tüm kurumlar için gereklidir. Özellikle başvuran hasta sayısının çok ve hasta grubunun da çeşitli olduğu hastaneler aslında aşı gereksinimi olan hasta popülasyonun da fazla olduğu hastanelerdir. Așlanma oranlarını gerekli seviyeye ulaştırabilmek için hastaneler bünyesinde bu merkezlerin aktif olarak çalışmalıdır.

Anahtar kelimeler: Erişkinlerde bağışıklama, bağışıklama

Sorumlu Yazar: İrem Akdemir Kalkan Ankara Ü., Tıp Fakültesi, Enfeksiyon Hastalıkları ve Klinik Mikrobiyoloji AD., Ankara, Türkiye, iremakd@yahoo.com

\section{Copyright holder Turkish Journal of Public Health}

This work is licensed under a Creative Commons Attribution-NonCommercial 4.0 International License. $(\mathrm{cc})$ EY-NC This is an open Access article which can be used if cited properly. 


\title{
Experiences of an adult vaccination centre in a second stage hospital
}

\begin{abstract}
Objective: Ensuring protection against vaccine-preventable diseases is important for public health. However, there are significant deficiencies in the practice of adult immunization in our country. In this study, we are sharing the experiences of the 'Adult Vaccination Centre' established in the Batman Regional State Hospital, which is a second step hospital. Methods: Hepatitis A, Hepatitis B and conjugated pneumococcal vaccines applied on the unit during the 3-month period between November 2017 and February 2018 were analysed for epidemiological characteristics, vaccine indications and referenced clinics. Results: A total of 85 patients were vaccinated. $35.3 \%$ $(\mathrm{n}=30)$ of these patients were female. All patients were older than 16 years. The mean age was 57.6 years. In the distribution of vaccines, $80 \%(n=68)$ of the patients were vaccinated with conjugated pneumococcal vaccine, $17.6 \%(n=15)$ had the hepatitis $B$ vaccine and $2.4 \%(n=2)$ had the hepatitis $A$ vaccine. When the indications for the vaccinations were considered, $5.9 \%(\mathrm{n}=$ $5)$ of the patients were over 65 years of age, $36.5 \%(n=31)$ of patients had renal failure, $1.2 \%(n$ $=1)$ had rheumatologic disease, $8.2 \%(n=7)$ individuals had risky contact with Hepatitis B, 4.7\% ( $n=4$ ) individuals were vaccinated because they were health staff and $42.4 \%(n=36)$ were individuals with underlying lung diseases, especially COPD. Conclusion: Adult Immunization Centres are required for all institutions providing secondary and tertiary health care. In order to increase the vaccination rates to the required level, these centres should be active within the hospitals.
\end{abstract}

Keywords: Adult vaccination, vaccination

\section{Giriş}

Bulaşıcı hastalıklar insanlık tarihi boyunca hep çok önemli olmuşlardır. Aşıların bu hastalık grubunun tarihçesinde en büyük değișimi sağladığı tartışmasız bir gerçektir. Aşılar sayesinde geçmişte çok ciddi mortalite ve morbidite nedeni olan Çiçek hastalığı eradike edilmiştir. Polio henüz eradike edilememiş olsa da dünyada görülme sıklığı önemli şekilde azalmıştır. Kızamık, kızamıkçık, kabakulak başta olmak üzere pek çok hastalık da aynı şekilde artık çok daha az oranlarda görülmektedir. Yine Hepatit B hastalığ infeksiyonları da oldukça az görülmektedir, dolayısı ile bu hastalıklara bağlı mortalite ve morbidite oranları da oldukça azalmıştır. ${ }^{1}$

Çocukluk dönemindeki yüksek aşılama oranları yüz güldürücü sonuçları sağlamışsa da erişkin dönemde hala özellikle tetanos, endemik bölgelerde Heptatit $B$ ve Hepatit A vakaları, özellikle risk altındaki kişilerde invaziv pnömokokal hastalık görülebilmektedir. Bu durumun en önemli nedeni aynı hasassiyet ve duyarlılığın erişkin bağışıklaması için gösterilmemesidir.
Ülkemizde çocukluk çağı aşılamaları birinci basamak sağlık kuruluşları tarafından kayıt altına alınarak yapılmaktadır ve oldukça başarılı bir şekilde hem hekim hem de yardımcı sağlık personeli tarafından takip edilmektedir. Erişkin aşılamaları ise ülkemizde 'Genişletilmiş Bağışılklama Programı' (GBP) çerçevesinde yürütülmektedir. Bu program kapsamında risk grubu için Hepatit B aşılaması, gebelik dönemi tetanos aşılaması, risk grubu için influenza ve pnömokok aşılamaları, Hac aşılamaları, sağlık personeli aşılamaları, erişkin tetanos aşı uygulamaları, seyahat aşılamaları doğurganlık çağı kadınlara tetanos ve kızamıkçı aşılamaları bulunmaktadır. Erişkin bağıșıklaması hem dünya genelinde hem de ülkemizde beklenilen seviyenin oldukça altındadır. Düzenli bir kayıt sistemi olmayışı, hekimlerin aşı önerme oranlarının düşük olması, hastaların aşı talep etme oranlarının düşük olması, aşıya ulaşım sorunları, kılavuzlar arası farklılıklar olması, erişkin bağışıklaması önündeki engeller olarak görünmektedir. 1,2,3 
Özellikle pek çok uzmanlık alanının hizmet verdiği ve hasta yoğunluğunun fazla olduğu kurumlarda bir erişkin bağışılklama merkezinin olması hem riskli bireylerin aşılanmasını sağlamak hem de takiplerini yapabilmek adına çok önemlidir. Ülkemizde bu kapsamda hizmet verebilen erişkin bağışıklama merkezleri bulunmaktadır. Fakat çoğunluğu büyük şehirlerde olan bu merkezlerin sayısı ülke geneli düşünüldüğünde maalesef oldukça yetersizdir.

$\mathrm{Bu}$ yazıda Batman Bölge Devlet Hastanesi bünyesinde Ekim 2017 de bir erişkin aşı merkezini faaliyete geçirdikten sonra yapılan aşılamalar ve edinilen tecrübeleri aktararak paylaşmayı amaçladık.

\section{Gereç ve Yöntem}

İnfeksiyon Hastalıkları ve Klinik Mikrobiyoloji ve özellikle immünsupresif tedavi veren Romatoloji, Onkoloji, Hematoloji ve böbrek yetmezliği nedeni ile immünitesi baskılı hastaların yoğun olarak izlendiği Nefroloji/Diyaliz üniteleri, sıklıkla pnömonili hasta takibi yapılan Göğüs Hastalıkları bölümlerinin hem poliklinik hem de yatan hasta servislerindeki erişkin bağışıklama ihtiyaçları göz önüne alınarak hastane bünyesinde bir erişkin aşılama ünitesi kurulması planlandı.

Toplamda üç ay süren çalışmalar sonucu öncelikle Sağlık Bakanlığı'na bağlı bir 'Așı Takip Sistemi' (ATS) ve aşı saklama koşullarına uygun bir buzdolabı temin edildi. Hastanemizde soğuk zincir ilaç sorumlusu olan eczacısı ile aşı temin edilmesi için İl Sağlık Müdürlüğü ile yazışmalar yapıldı. Hastanede çalışmakta olan aşı konusunda deneyimli ve aynı zamanda hastanenin soğuk zincir sorumlularından olan bir hemşire, bu konu ile ilgili sorumlu olarak görevlendirildi. Birimin hekim sorumlusu olarak ise İnfeksiyon Hastalıkları ve Klinik Mikrobiyoloji uzmanları belirlendi. Yapılması planlanan aşılar hakkında formlar hazırlanılarak uygulayıcı olacak üç hemşireye gerekli eğitimler verildi. Öncelikle İl Sağlık Müdürlügünden Hepatit B, Hepatit A ve konjuge pnömokok aşıları temin edildi. Bunlar dışındaki aşıların ihtiyaç durumunda temin edilmesi için gerekli girişimler yapıldı. Hastane acil servisinde yürütülmekte olan tetanos ve kuduz aşılamaları ise birimin kapsamı dışında tutuldu. Hekimlerin hasta yönlendirirken doldurmaları gereken bir form hazırlandı. Hastanın; isim, protokol no, yapılması istenilen aşı ve endikasyonunun yer aldığı bu formun hekim kașesi ile erişkin aşı birimine yönlendirmesini takiben aşı uygulandı. Hastanede çalışan tüm hekimlere çeşitli yazılı olarak ve elektronik ortamda çeşitli duyurular yaplarak birimin kurulduğuna dair bilgilendirmeler yapıldı. Yapılacak aşı ile ilgili temel bilgileri aşıya yönlendiren hekimin vermesi, hastalardan onam alması ve așı uygulayan hemșirenin de hastaya uygulamaya yönelik bilgi vermesi sağlandı. Hastanede görev yapan hekimlere yönelik olarak, uygulanacak aşılara yönelik genel ve özel durumlar ile ilgili eğitim toplantıları düzenlendi. Bu eğitimlere on beş hekim katıldı. Yapılacak tüm aşılar önceden hazırlığ tamamlanan ATS sistemi kapsamında kayıt altına alınarak uygulandı.

Çalışma öncesinde Bölge Devlet Hastanesi Etik Kurul biriminden etik kurul onayı alınmıștır.

\section{Bulgular}

Yapılan uygulamaların kayıtlarının retrospektif incelemesinde Kasım 2017 Şubat 2018 sürecinde toplamda 85 hastaya aşı yapıldığı saptandı. Bu hastaların \%35.3'ü $(n=30)$ kadın idi. Hastaların tümü 16 yaş üzeri idi. Yaş ortalaması 57.6 olup en genç hasta 18 yaşında en yaşlı hasta ise 91 yaşında idi.

Yapılan aşıların dağılımına bakıldığında \%80 (n=68) hastanın konjuge pnömokok aşısı ile aşılandığı, \%17.6 (n=15) hastaya Hepatit B , \%2.4 (n=2) hastaya ise hepatit $A$ aşısı uygulandığı görüldü.

Aşılama endikasyonlarına bakıldığında \%5.9 (n=5) hasta 65 yaş üstü olması nedeni ile \%36.5 (n=31)hasta böbrek yetmezliği nedeni yle, \%1.2 (n=1) hasta romatolojik tedavi adayı olması nedeni yle, \%8.2 ( $\mathrm{n=7}$ ) birey evde riskli temaslı bireytümü Hepatit B açısından- olması nedeni yle, \%4.7 $(\mathrm{n}=4)$ birey ise sağllk personeli olduğu için aşılanırken, \%42.4 $(n=36)$ birey ise başta 
KOAH olmak üzere altta yatan akciğer hastalıkları nedeni ile aşılanmışlardı.

Așı uygulanan bireylerden \%38.8'i $(n=33)$ farklı endikasyonlar ile yönlendirilmiş olmalarına rağmen aynı zamanda 65 yaş üzeri olmaları nedeni ile de aşı endikasyonu olan bireylerdi. $\mathrm{Bu}$ yaş grubuna uygulanan tüm aşılar ise pnömokok aşısı idi.

Hastaların yönlendirildiği polikliniklere bakıldığında \%37.6 $(\mathrm{n}=32)$ hasta Nefroloji, \%42.4 (n=36) hasta ise Göğüs Hastalıkları polikliniğinden yönlendirilirken, İnfeksiyon Hastalıkları ve Klinik Mikrobiyoloji polikliniğinden \%16.5 $(\mathrm{n}=14)$ hasta yönlendirilmiști.

Hepatit A ve B aşıları için yönlendirilen hastaların aşı takvimleri planlandı ve hastaların tekrar gelecekleri tarihler belirlendi. İlk dozları ünitede yapılan \%4.7 ( $\mathrm{n}=4)$ hastanın Hepatit B aşısının ikinci dozları da de bu süreç içinde yine bu merkezde yapıldı. Diğer kişiler ise aşı semasının tamamlanması için birinci basamak aile hekimliklerine yönlendirilmiş olarak saptandı. Konjuge pnömokok aşısı uygulanan hastalardan riskli grupta olan (splenektomili ve immunsupresif tedavi adayı birer hasta) toplamda 2 hastaya, 8 hafta sonra polisakkarit aşılama için gün verildi ve aşı uygulandı. Diğer hastalara ise 1 yıl sonrası için polisakkarit aşı için başvuru tarihi aşı kartına işlendi.

Aşı uygulanan tüm hastalar için düzenlenen aşı kartı kendilerine verildi. İleriki tarihlerde yapılması gereken dozlar için başvuru tarihleri de hem aşı kartlarına hem de hastane kayıtlarına hastaların iletişim bilgileri ile birlikte kaydedildi.

Aşı uygulaması yapılan tüm hastalar 30 dakika boyunca hastanede gözlemlendi ve hiçbir hastada alerji/anaflaksi gelişmedi. Aşı uygulanan hastalar içerisinde İnfeksiyon Hastalıkları ve Klinik Mikrobiyoloji polikliniğine aşı yan etkisi şikayeti ile başvuran hasta olmadi.

\section{Tartışma}

Erişkin aşı uygulamaları en gelişmiş olarak kabul edilen ülkelerde dahi hedeflenen seviyede değildir. Son ylllarda ülkemizde erișkin aşılaması konusunda hem farkındalık artmış hem de bunun sonucu olarak yapılan uygulamalar çeşitlenmiştir. Bununla beraber hala aşı uygulamaları ülkemizde kapsayıcılığı oldukça düşük olan uygulamalar olarak görünmektedir. 4,5,6

İkinci basamak sağlık kuruluşları ve hatta üçüncü basamak kuruluşlar ülkemizdeki rutin işleyiște erişkinlere aşı uygulamasının sık yapıldığı yerler değildir. Aşı ihtiyacı olan kişiler genellikle birinci basamak hekimlerine yönlendirilir ve bunların takibi ikinci basamak hekimleri /uzman hekimler tarafindan siklıkla yapılamamaktadır. Bu durumda hastaların izlenmesinde, bağıșıklığın sağlanmasında, özel durumlara ait öneri ve yönlendirmeler yapılmasinda zorluklar ve eksiklikler olmaktadır. Diğer taraftan hem İnfeksiyon Hastalıkları ve Klinik Mikrobiyoloji uzmanları hem de diğer branș hekimleri iş yoğunlukları ve bilgi eksiklikleri nedeni ile erişkin bağışıklamasının önemini yeterince özümseyemeyebilirler.

Uygulamaları optimize edebilmek için öncelikle standart yaklaşımları tüm uzmanlık alanları ile birlikte benimseyip aşıları da kolay ulaşılabilir hale getirmek en önemli noktalardandır. Hastanemizde kurulan aşı merkezi ile 4 ayda 85 kişinin aşılarının yapılmış olması bu alanda bir ihtiyaç olduğunu net şekilde ortaya koymaktadır. Özellikle Nefroloji ve Göğüs Hastalıkları polikliniklerinden aşı birimine yönlendirilen hastaların fazla oluşu aşı endikasyonlarının ciddiyeti de göz önüne alındığında çok önemlidir. Diğer taraftan bu dört aylık süreç boyunca hastaneye başvuran hasta sayılarının kaydı da istatistik biriminden alınmıştır. Buna göre çalışma süresindeki dört ay boyunca hastaneye 539.705 poliklinik başvurusu olmuş ve 9322 hastane yatışı olmuştur. Bu grubun poliklinik muayenesinde 67.416'sl, yatan hastalarda ise 2080 kişisi 65 yaş üzeri bireylerdir. Sadece Enfeksiyon Hastalıkları ve Klinik Mikrobiyoloji bölümünün rakamlarına bakıldığında ise süreç boyunca 5024 toplam poliklinik girişi ve 101 yatan hasta olmuştur. $\mathrm{Bu}$ grubun da poliklinikteki 1238 kişisi ve yatan hastaların da 18 kişisi 65 yaş üzerindeki bireylerdir. $\mathrm{Bu}$ pencereden bakıldığında ise; sadece 65 yaş üzeri 
endikasyonu ve pnömokok aşısı için dahi çok daha yüksek oranda aşı gerekliliği olan birey hastaneye başvurmuş ama bunların çok düşük bir bölümü aşılanabilmiştir. Hasta başvuru kayıtları incelendiğinde Dahiliye ve Genel Cerrahi gibi yoğun poliklinik ve yatış olan bölümlerden hiç hasta yönlendirilmemiştir. Enfeksiyon Hastalıkları uzmanları dışındaki hekimlerin bağışıklama konusundaki bilgi ve farkındalıklarının düşük olduğu düşünülebilir. Diğer taraftan Enfeksiyon Hastalıkları polikliniğinden yönlendirilen kişi sayısı da aşı ihtiyacı olan birey sayısı ile kıyaslandığında oldukça düşüktür.

Sonuç olarak 'Erişkin Bağıșıklama Merkezleri' ikinci ve üçüncü basamak sağlık hizmeti veren tüm kurumlar için gereklidir. Özellikle başvuran hasta sayısının çok ve hasta grubunun da çeşitli olduğu hastaneler aslında aşı gereksinimi olan hasta popülasyonun da fazla olduğu hastanelerdir. Aşılanma oranlarını gerekli seviyeye ulaştırabilmek için hastaneler bünyesinde bu merkezlerin aktif olarak çalışmalıdır. Yüksek aşılanma oranları ancak aktif çalışan merkezlerin varlığında ve bu konuda duyarlılığı, farkındalığı da fazla olan hekimlerin gerekli özeni göstermesi ile mümkün olabilecektir. Ülkemiz çocukluk çağı aşı uygulamalarında 'Genişletilmiş Bağışıklama Uygulamaları' genelgesi ile \%96'nın üzerinde aşılanma oranlarına ulaşabilirken, benzer şekilde bir 'Erişkin Bağışıklama Genelgesi' oluşturulabilirse bu önemli konunun çerçevesi daha net çizilmiş olacaktır. Aşı konusunda hekimlerde farkındalık yaratmak için düzenlenecek tüm faaliyetler aynı zamanda bu konudaki duyarlılığı da artıracaktır.

\section{Kaynaklar}

1. WHO | Vaccines and diseases. WHO [Internet]. 2018 [cited 2018 Mar 10]; Available from: http://www.who.int/immunization/disease s/en/

2. Sağlık Bakanlığı, Türkiye Halk Sağlığı Kurumu. Risk Grubu Așlamaları. Tarih: 27.05.2016, Sayl: 21001706/131.99. http://asirehberi.saglik.gov.tr/?/griskgrubu (Erişim Tarihi: 28.06.2018)

3.Adult Immunization Schedule by Vaccine and Age Group | CDC [Internet]. [cited 2018 Mar 10]. Available from: https://www.cdc.gov/vaccines/schedules/ hcp/imz/adult.html

4.WHO | Global Vaccine Action Plan. WHO [Internet]. 2018 [cited 2018 Mar 10]; Available from: http://www.who.int/immunization/global_ vaccine_action_plan/en/

5.WHO | Data, statistics and graphics. WHO [Internet]. 2018 [cited 2018 Mar 10]; Available from: http://www.who.int/immunization/monito ring_surveillance/data/en/

6.Alici, D. E., Sayiner, A., \& Unal, S. (2016). Barriers to adult immunization and solutions: Personalized approaches. Human vaccines \& immunotherapeutics, 13(1), 213215. doi:10.1080/21645515.2016.1234556 